\title{
Validity of a two-item physical activity questionnaire for assessing attainment of physical activity guidelines in youth
}

\author{
Michelle Hardie Murphy ${ }^{1}$, David A. Rowe ${ }^{2}$, Sarahjane Belton ${ }^{1}$ and Catherine B. Woods ${ }^{1 *}$
}

\begin{abstract}
Background: As physical activity is important for health and well-being, it is essential to monitor population prevalence of physical activity. Surveillance is dependent on the use of valid and reliable measurement tools. The PACE+ questionnaire is used globally in youth and has acceptable reliability; however it has not been validated in a European sample. The purpose of this study is to validate this instrument in a sample of 10-18 year old Irish youth.

Methods: Participants ( $n=419,45.7 \%$ male) completed the PACE+ two-item questionnaire and were asked to wear an Actigraph accelerometer for eight consecutive days. Freedson cut-points were used to estimate moderate to vigorous physical activity from accelerometer counts. Analyses compared self-report and accelerometry data in participants with (1) $\geq 5$ and (2) seven valid accelerometer days. Calculations were performed for the whole sample, and were stratified by sex and school level (primary; post-primary).

Results: Spearman correlations between self-reported physical activity levels and accelerometry derived minutes of moderate-to-vigorous physical activity per day were small ( $r=0.27$; seven valid days) to moderate $(r=0.34$; $\geq 5$ valid days). Higher correlations were found in older participants (post-primary $r=0.39$; primary $r=0.24)$ and females $(r=0.39$; males $r=0.27$ ) using $\geq 5$ valid days. The agreement level was high (68-96\%). The accuracy of classifying those not meeting the guidelines (specificity) was moderate to high (59-100\%).

Conclusions: The PACE+ self-report instrument has acceptable validity for assessing non-achievement of the adolescent physical activity recommendations. The validity is higher in females and increases with age. The continued use of the tool is recommended and will allow for comparability between studies, tracking of physical activity over time including trends in youth population prevalence.
\end{abstract}

Keywords: Physical activity, Validity, Youth, Adolescence, Epidemiology

\section{Background}

The benefits of physical activity (PA) to health are widely documented [1]. Monitoring and surveillance of population prevalence are of paramount importance [2] and vital for the progression of PA and public health [3]. Due to the complexity and multifaceted nature of PA, measurement of this behaviour can be challenging [4]. Valid and reliable PA measurement is essential for establishing prevalence, including trends over time [5], and verifying if efforts to promote PA are having a positive

\footnotetext{
* Correspondence: catherine.woods@dcu.ie

'School of Health and Human Performance, Dublin City University, Dublin 9 Ireland

Full list of author information is available at the end of the article
}

influence [6]. Prevalence rates are dependent on the instrument used to measure it [7]. The process of selecting a suitable questionnaire is based on two fundamental criteria; validity and reliability of the instrument [8]. The use of one valid and reliable tool across many countries would provide consistency and comparability of findings [9]. Such an instrument would need to be simple and adept at assessing compliance with physical activity guidelines (PAGL) for health at a population level [10]. In youth aged 5-18 years, the PAGL stand at a minimum of 60 minutes of moderate-to-vigorous physical activity (MVPA) on every day of the week [1]. Although PAGL were developed using predominantly self-report data [11], due to the limitations of self-report measures in youth, 
validation of these measures with accelerometers is commonplace $[6,10,12-16]$. This combined approach to the assessment of PAGL compliance provides for informed discussion on the accuracy of prevalence estimates.

In epidemiology, self-report questionnaires are frequently used due to their low cost and convenience [17]. Ease of administration is a factor determining survey choice for large scale studies [18]. A brief two-item PA screening tool (PACE+) was designed for use in adolescents [12]. The tool was first developed for use in a primary care setting with the function of identifying individuals not meeting the PAGL and who, from a health perspective, could benefit from intervention. It assesses the number of days adolescents engage in a minimum of 60 minutes of MVPA and is used as an indicator of habitual PA. It does not aim to describe PA behaviour beyond this. This instrument is widely used across the globe. It is utilised by 43 countries in the WHO HBSC questionnaire [19], and by up to 94 countries in the Global School-based Student Health Study [20-22] and other studies [23-26].

Test-retest reliability has been conducted on the instrument. In a Finnish study, it was assessed alongside a vigorous PA item. It was found to have acceptable reliability with intraclass correlation coefficients (ICC) ranging from 0.6 to 0.8 [27]. In a Chinese study with a sample of 11 and 15 year olds, an ICC of 0.82 (95\% CI 0.74-0.88) was reported for the first item (MVPA in the last seven days) and an ICC of 0.74 (95 \% CI 0.64-0.82) for the second item (MVPA in a usual week) [28]. More recently, the tool showed moderate reliability, in the same age groups, with an ICC ranging from 0.51 to 0.98 in three Eastern European countries. The ICC for the whole sample was 0.60 (95\% CI 0.55-0.64) [29]. No significant sex or age differences were noted in the Chinese or European studies described. These studies address the reliability of the PACE+ but not its validity.

Elsewhere it has been validated via correlations with accelerometer derived MVPA. It demonstrated moderate validity in a sample of 11-13 year old youth in the U.S. $(r=0.40, p<0.001$; test-retest ICC $=0.77)[12]$ and later in an Australian sample of $15-17$ year olds $(r=0.40$ with five days accelerometer data, $r=0.49$ with seven days accelerometer data) [10].

Questionnaires appraised in one population cannot be systematically transferred to other geographical regions or populations [17]. There is a strong need for assessment of the validity of these items across the regions which utilise it [29]. Particularly as results from studies using this instrument are used for health promoting strategies and policies targeting youth [19]. It is also essential to validate it across all adolescent years. The need for further studies that investigate the validity of this instrument using objective PA monitoring has been highlighted in the literature [29]. The purpose of the study was to examine the validity of the PACE+ questionnaire for assessing physical activity, and attainment of the European physical activity recommendations of 60 minutes of MVPA per day through accelerometry.

\section{Methods}

This study was conducted within the Children's Sport Participation and Physical Activity (CSPPA) Study [23]. Initially, data were collected from a nationally representative sample $(N=5397)$ of youth from the Republic of Ireland using a systematic, one-stage cluster sampling method. A follow-up study took place five years after the original study. The validation study included a convenience sample of 419 participants $(n=284$ from 2009; $n=135$ from 2014) from 19 schools. Standardised procedures were adopted during data collection in 2009 and 2014 (both February - May). Dublin City University's Research Ethics Committee approved the study in 2009 and 2014. Written informed consent was obtained from adolescents aged 18 years and written assent, in addition to, parental consent was gathered from participants $<18$ years.

Participants completed a self-report questionnaire, which included demographic information (sex, date of birth, nationality, area of residence and social class) as well as the PACE+ questions. Questionnaires were administered in primary ( $5^{\text {th }}$ and $6^{\text {th }}$ class; age $10-12$ years) and postprimary $\left(1^{\text {st }}\right.$ to $6^{\text {th }}$ year; age $12-18$ years) schools, from across the Republic of Ireland, in the presence of a research team member. Participants were provided with definitions of moderate and vigorous effort and instructed to only include activities of this intensity when completing the PACE+ questions. The first item asked them to report the number of days (0-7) they were physically active for at least 60 minutes per day in the past seven days. The second item asked the same question with respect to a typical or usual week [12]. An average value of the two items yielded a score of days per week that participants accumulated 60 minutes of MVPA. Compliance with PA recommendations was assessed in two ways; by creating binary variables for those achieving/not achieving $\geq 5$ days MVPA and 7 days MVPA.

Additionally, PA was objectively measured using the ActiGraph accelerometer (GT1M and GT3X). This monitor is an acceptable criterion measure for evaluating questionnaire validity [30] and the most widely used for this purpose [17]. Accelerometers were distributed to participants on the same day as questionnaire completion. Participants were instructed to wear the devices for eight consecutive days on their right hip during all waking hours, except for when they were swimming or bathing. The eighth day was excluded from analysis as accelerometers were collected during the daytime. The epoch length was set at $15 \mathrm{~s}$. Data from the devices were downloaded 
and cleaned using ActiLife software. Consecutive zero counts of 20 minutes or more were eliminated from total wear time.

Accelerometer data were analysed using Freedson agespecific cut points $[31,32]$ which have demonstrated excellent specificity and sensitivity for MVPA [33]. Similar to the NHANES study [34] and the validation study by Ridgers and colleagues [10], a threshold of four METs for moderate activity was chosen. A summary score of counts per min (CPM) represented total PA. For comparability purposes, compliance with PA recommendations was established using the same two methods as Ridgers and colleagues [10]; the average method and the all days method. In the average method (AM), the average minutes of MVPA per valid days was calculated and dichotomised as above or below $60 \mathrm{mins} /$ day. In the all days method (ADM), valid days that participants engaged in $\geq 60$ min of MVPA was determined and dichotomised into those meeting/not meeting (a) $\geq 5$ days and (b) 7 days.

\section{Statistical analysis}

Descriptive statistics were calculated for demographic, self-report and accelerometer data. For inclusion in the study, participants were required to have complete selfreport data and meet accelerometer wear time criteria of a minimum of eight hours per day on at least five days. The sample that met inclusion criteria was compared to the full sample for sex, age, school level and selfreported days of $\geq 60$ minutes of MVPA. All statistical analyses were performed for the whole sample and stratified by sex and school level. All calculations were completed using those with (a) $\geq 5$ valid accelerometer days ( $n=235 ; 41.3 \%$ male) and (b) a subsample with seven valid accelerometer days $(n=77 ; 36.4 \%$ male). Spearman rho correlation coefficients were calculated between self-report (average days 60mins MVPA) and accelerometry data (mins of MVPA/day; CPM). The strength of the correlations were ranked as small $(>0.1)$, moderate $(>0.3)$ and strong $(>0.5)$ [35]. The percent agreement between self-report and accelerometry was established by assessing the consistency of the classification of achieving the PAGL between the two methods. Sensitivity was defined as the accuracy of classifying those achieving the PAGL. Specificity referred to the accuracy of classifying those who did not meet the PAGL. The positive predictive value (PPV) is the percentage who self-reported meeting PAGL who actually met the guidelines and the negative predictive value (NPV) is the percentage who self-reported not meeting PAGL who did not actually meet the guidelines [36]. All analyses were performed using SPSS v.21 (IBM Corp, Armonk, NY).

\section{Results}

Of the 419 youth ( $45.7 \%$ male) aged $10-18$ years who participated in the study, $56.1 \%(n=235 ; 41.3 \%$ male; $14.7 \pm 3.1$ years) met the inclusion criteria. Participants were excluded from the analysis if they were missing one item of the screening tool $(n=6)$ or if they did not meet accelerometer wear time criteria $(n=175)$. A malfunction in accelerometer files led to the loss of three participants. Participants attended both primary (37\%; $11.2 \pm 0.4$ years) and post-primary (63\%; $16.8 \pm 1.9$ years) school levels. Table 1 presents the participant characteristics.

There were no significant differences between the final sample and those excluded in terms of age $(\mathrm{t}(414)=0.84$, $p=0.40)$, school level $\left(X^{2}(1)=1.38, p=0.14\right)$ or selfreported days of $60 \mathrm{~min}$ MVPA $(\mathrm{t}(407)=0.16, p=0.87)$. However, a difference in sex was found $(p=0.03)$ with girls more likely to comply with wearing the accelerometer than boys (61.1 vs. $51.1 \%$ ).

Table 2 shows PA levels and compliance with PAGL for both self-report and accelerometer data. Across participant groups, the proportion meeting PAGL on all days of the week was low in both self-report (4-8 \%) and accelerometry (AM 12-25\%; ADM 0-2 \%). Rates were higher for meeting PAGL on $\geq 5$ days per week (self-report 30-45 \%; AM 12-32 \%; ADM 6-16\%). Males had significantly $(p<0.01)$ higher values than females for MVPA mins/day, CPM and self-reported days of PA for $\geq 5$ valid accelerometer days but not for seven days of data. Primary level students scored higher than

Table 1 Descriptive characteristics of study participants

\begin{tabular}{|c|c|c|c|c|}
\hline & \multirow{3}{*}{$\begin{array}{l}\text { Full sample } \\
n=419\end{array}$} & \multicolumn{3}{|c|}{ Included sample } \\
\hline & & Primary & Post-primary & Total \\
\hline & & $n=87$ & $n=148$ & $n=235$ \\
\hline Age (mean $\pm S D)$ & $14.8 \pm 3.1$ & $11.2 \pm 0.4$ & $16.8 \pm 1.9$ & $14.7 \pm 3.1$ \\
\hline Age (range) & $10-18$ & $10-12$ & $12-18$ & $10-18$ \\
\hline \multicolumn{5}{|l|}{ Sex $(\%)$} \\
\hline Male & 45.7 & 32.2 & 46.6 & 41.3 \\
\hline Female & 54.3 & 67.8 & 53.4 & 58.7 \\
\hline \multicolumn{5}{|l|}{ Nationality (\%) } \\
\hline Irish & 93.8 & 93.1 & 91.9 & 92.3 \\
\hline Other & 6.2 & 6.9 & 8.1 & 7.7 \\
\hline \multicolumn{5}{|c|}{ Area of residence (\%) } \\
\hline Urban & 43.4 & 57.6 & 41.5 & 47.4 \\
\hline Rural & 56.6 & 42.4 & 58.5 & 52.6 \\
\hline \multicolumn{5}{|l|}{ Social class (\%) } \\
\hline Low & 9.4 & 9.3 & 9.3 & 9.2 \\
\hline Medium & 37.7 & 41.9 & 36.9 & 38.9 \\
\hline High & 47.6 & 40.7 & 50 & 46.3 \\
\hline Unknown & 5.3 & 8.1 & 3.8 & 5.6 \\
\hline
\end{tabular}


Table 2 Physical activity levels and proportion achieving physical activity recommendations assessed by self-report and accelerometry

\begin{tabular}{|c|c|c|c|c|c|}
\hline & Total & Males & Females & Primary & Post-Primary \\
\hline$\geq 5$ valid accelerometer days & $n=235$ & $n=97$ & $n=138$ & $n=87$ & $n=148$ \\
\hline \multicolumn{6}{|l|}{ Physical activity levels (mean \pm SD) } \\
\hline MVPA (mins/day) & $40.8 \pm 28.7$ & $47.2 \pm 34.5$ & $36.3 \pm 22.9$ & $57.9 \pm 24.1$ & $30.8 \pm 26.5$ \\
\hline Total PA (CPM) $)^{\mathrm{a}}$ & $238.5 \pm 111.7$ & $267.0 \pm 123.2$ & $218.5 \pm 98.4$ & $271.1 \pm 86.9$ & $219.4 \pm 120.2$ \\
\hline Self-reported PA (days) $)^{b}$ & $4.0 \pm 1.7$ & $4.6 \pm 1.5$ & $3.7 \pm 1.8$ & $4.3 \pm 1.4$ & $3.9 \pm 1.9$ \\
\hline \multicolumn{6}{|l|}{ Meeting 5 day PA recommendations (\%) } \\
\hline Self-reported PA $\geq 5$ days ${ }^{\mathrm{c}}$ & 36.6 & 45.3 & 29.7 & 42.4 & 32.5 \\
\hline 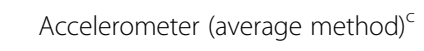 & 19.6 & 30.9 & 11.6 & 32.2 & 12.2 \\
\hline Accelerometer (all days method) $)^{d}$ & 9.8 & 15.5 & 5.8 & 14.9 & 6.8 \\
\hline Seven valid accelerometer days & $n=77$ & $n=28$ & $n=49$ & $n=28$ & $n=49$ \\
\hline \multicolumn{6}{|l|}{ Physical activity levels (mean \pm SD) } \\
\hline MVPA (mins/day) & $38.7 \pm 26.2$ & $41.7 \pm 30.2$ & $37.0 \pm 23.8$ & $51.7 \pm 16.4$ & $31.3 \pm 28.0$ \\
\hline Total PA (CPM) ${ }^{\mathrm{a}}$ & $223.5 \pm 100.7$ & $237.1 \pm 106.9$ & $215.7 \pm 97.2$ & $245.0 \pm 58.8$ & $211.1 \pm 117.0$ \\
\hline Self-reported PA (days) ${ }^{b}$ & $3.9 \pm 1.7$ & $4.2 \pm 1.6$ & $3.7 \pm 1.8$ & $4.2 \pm 1.2$ & $3.7 \pm 1.9$ \\
\hline \multicolumn{6}{|l|}{ Meeting 7 day PA recommendations (\%) } \\
\hline Self-reported $\mathrm{PA}=7$ days & 5.2 & 7.1 & 4.1 & 3.6 & 8.2 \\
\hline Accelerometer (average method) $^{c}$ & 16.9 & 25.0 & 12.2 & 25 & 12.2 \\
\hline Accelerometer (all days method) ${ }^{\mathrm{e}}$ & 1.3 & 0 & 2.0 & 0 & 2.0 \\
\hline
\end{tabular}

${ }^{\mathrm{a}} \mathrm{CPM}=$ counts per minute

${ }^{b}$ Self-reported PA: composite score of the two self-report items for days per week achieving 60 min MVPA

${ }^{C}$ Average method (AM): proportion achieving an average of $60 \mathrm{~min}$ or more of MVPA across all valid days

${ }^{\mathrm{d}}$ All days method (ADM $\geq 5$ days): proportion achieving $\geq 60 \mathrm{~min}$ MVPA on at least 5 days

${ }^{\mathrm{e}}$ All days method (ADM 7 days): proportion achieving $\geq 60$ min MVPA on all 7 days

post-primary students $(p<0.01)$ for MVPA mins/day $(\geq 5$ and 7 days) and total PA ( $\geq 5$ days only).

Correlation coefficients were small to moderate $(r=$ $0.27-0.34$ ) between self-reported days meeting 60 minutes of MVPA and accelerometer data in terms of minutes of MVPA per day and total PA per day in the whole sample (Table 3). Stronger correlations were found in older participants (post-primary, $r=0.36-0.39$; primary, $r=-0.12-$ $0.25)$ and girls $(r=0.38-0.41$; males, $r=0.10-0.27)$ using both $\geq 5$ and seven days. Correlations were significant for girls, post-primary students and the total sample using seven accelerometer days and in all groups using $\geq 5$ days.

Details of agreement, sensitivity, positive predictive value (PPV), specificity and negative predictive value (NPV) between self-reported PA and accelerometer data are displayed in Table 4. There was a high level of agreement between the PACE+ and accelerometer data. Using the AM, the agreement level was $68-85 \%$ for $\geq 5$ valid days and 71-82\% for seven days. For the ADM, agreement was $89-91 \%$ for $\geq 5$ days and $88-96 \%$ for seven days of accelerometer data. Overall, the accuracy of classifying those achieving the guidelines (sensitivity) was low to moderate ( $\geq 5$ days; $38-67 \%$ accuracy) and in some cases not computable due to a lack of participants meeting the PAGL (7 days; not computable to $17 \%$ accuracy). Values were higher in males than females (AM 67 vs.
$38 \%$; ADM 67 vs. $50 \%$ ). The percentage of male and primary students who self-reported meeting the PAGL, who actually met them (PPV; 9-50\%) was higher than in female and post-primary students. The accuracy of classifying those not meeting the guidelines (specificity) was moderate ( $\geq 5$ days; $59-72 \%$ accuracy) to high (7 days; 92-100\% accuracy). The NPV was high (74-100\%) across all analyses.

\section{Discussion}

The purpose of this study was to examine the validity of a short questionnaire for assessing attainment and nonattainment of the youth PA recommendations among Irish youth.

Overall, the self-report questionnaire was moderately correlated with accelerometer data in terms of MVPA mins/day and CPM. The validity of the instrument was highest in girls and older adolescents. The low correlations in the younger group (primary) are consistent with findings in the literature [37]. A systematic review of PA questionnaires in youth revealed that adolescents' selfreport data correlated better with accelerometer scores than children's [38]. This may be explained by their cognitive maturity and enhanced ability to recall PA with age [39]. 
Table 3 Spearman rho correlations between self-reported and accelerometry recorded physical activity levels

\begin{tabular}{|c|c|c|c|}
\hline & \multirow[b]{2}{*}{ (n) } & \multicolumn{2}{|l|}{ Self-reported PA ${ }^{a}$} \\
\hline & & MVPA (mins/day) $)^{b}$ & Total PA (CPM) \\
\hline \multicolumn{4}{|c|}{$\geq 5$ valid accelerometer days } \\
\hline Total & 235 & $0.34^{* *}$ & $0.33^{* *}$ \\
\hline \multicolumn{4}{|l|}{ Sex } \\
\hline Male & 97 & $0.27^{* *}$ & $0.25^{*}$ \\
\hline Female & 138 & $0.39^{* *}$ & $0.38^{* *}$ \\
\hline \multicolumn{4}{|l|}{ School level } \\
\hline Primary & 87 & $0.24^{*}$ & $0.25^{*}$ \\
\hline Post primary & 148 & $0.39^{* *}$ & $0.36^{* *}$ \\
\hline \multicolumn{4}{|c|}{ Seven valid accelerometer days } \\
\hline Total & 77 & $0.27^{*}$ & $0.30^{* *}$ \\
\hline \multicolumn{4}{|l|}{ Sex } \\
\hline Male & 28 & 0.10 & 0.16 \\
\hline Female & 49 & $0.40^{* *}$ & $0.41^{* *}$ \\
\hline \multicolumn{4}{|l|}{ School level } \\
\hline Primary & 28 & -0.12 & -0.10 \\
\hline Post primary & 49 & $0.39^{* *}$ & $0.39^{* *}$ \\
\hline
\end{tabular}

${ }^{a}$ Self-reported PA: days per week achieving 60 minutes of MVPA

${ }^{\mathrm{b}}$ Accelerometer derived average minutes of MVPA per day (MVPA mins/day)

${ }^{c}$ Accelerometer counts per minute (CPM)

${ }^{*} p<0.05$

${ }^{* *} p<0.01$

The agreement level was high and varied across the different methods of analysis. As expected, the percent agreement was consistently higher using the ADM ( $\geq 88 \%$ ) than the AM (68-85 \%). This illustrates a strong agreement between self-report and accelerometer data for detecting whether adolescents engage in the recommended levels of PA. Sensitivity results were low using the seven-days criteria, and in many cases it was noncomputable. This can be attributed to the small proportions actually meeting the PAGL. Consequently, these results should be viewed with caution. Higher values in boys may be explained by the higher PA levels in boys than girls, and therefore, greater proportions meeting the PAGL. Similar trends were found for PPV. On the contrary, the accuracy of classifying those not meeting the PAGL (specificity) was moderate to high, and the NPV was consistently high. As specificity and sensitivity are inversely proportional [36], it is unsurprising that results for specificity are much higher. Nonetheless, it is important to identify this group for health promoting efforts.

To date, two studies aimed to validate this measurement tool, the first in a U.S. sample [12] and the second in a sample of Australian youth [10]. In the U.S. study [12], the overall correlations - based on PAGL on $\geq 5$ days per week only - were greater than the current study ( 0.40 vs. 0.34 ). Similar ages between the post-primary students in the current study and the sample in the Australian study allow for direct comparison. Overall correlations were similar for MVPA mins/day (0.40 (Australia) vs. 0.39 (Ireland)) and for CPM (0.42 vs. 0.36$)$ using $\geq 5$ valid days. Correlations reported in both the U.S. and Australian papers can be described as moderate.

The overall agreement level was higher in the current study (78-90\%) than in the other two papers $(63 \%$ and 72-88 \%). Higher sensitivity values in the Australian study are due to higher proportions meeting the PAGL. In the total sample, specificity was higher in this study compared with the Australian study over seven days but lower in the $\geq 5$ days analysis. Regardless, specificity was good in both.

Furthermore, it is necessary to compare the PACE+ with other available self-report questionnaires. In the literature, Spearman rho correlations are the most commonly used measure of criterion validity for self-report instruments [17]. Review studies on PA questionnaires developed for use in children and adolescents found that the majority of instruments have acceptable reliability, and validity is low to moderate at best [40]. A systematic review found median validity correlations ranged from 0.22 to 0.41 [17]. All of these studies have a range of PA outcome measures including PA summary scores, total minutes of PA, MET minutes and MVPA minutes per day. Any of these measures can be used to categorise the respondent into meeting PAGL versus not meeting. A separate review of 89 PA measures for population surveillance in youth approved three study questionnaires, two of which contained the PACE+ [18]. In these studies, the PACE+ was used alongside other measures that describe PA behaviour.

The issue of overestimation of PA by subjective recall methods is frequently raised in the literature. A systematic review revealed that of those studied, $72 \%$ of indirect PA measures overestimated objectively measured values [40]. In this study, the proportion achieving 60 minutes of MVPA on $\geq 5$ days per week was higher in self-report than objective measurement. However, a reverse of this occurs when examining seven days. The averaging of two items to form the self-report score could potentially create a confounding effect by making it harder to achieve seven days.

In relation to PA levels, the self-reported levels described here are comparable to those found in a nationally representative sample of Irish students $(n=5397$; aged 10-18years) from which these participants are extracted [23]. The mean days meeting 60 minutes of MVPA $(4.0 \pm 1.7$ and $4.0 \pm 1.8)$ were very similar. Likewise, PA was higher in boys than girls and decreased with age. The 
Table 4 Agreement, sensitivity and specificity between self-reported physical activity and accelerometer data for compliance with recommendations

\begin{tabular}{|c|c|c|c|c|c|c|c|c|c|c|}
\hline & \multicolumn{5}{|c|}{$\geq 5$ valid accelerometer days $(n=235)$} & \multicolumn{5}{|c|}{ Seven valid accelerometer days $(n=77)$} \\
\hline & Agreement & Sensitivity & $\mathrm{PPV}^{\mathrm{C}}$ & Specificity & $\overline{N P V^{d}}$ & Agreement & Sensitivity & $\mathrm{PPV}^{\mathrm{C}}$ & Specificity & $\mathrm{NPV}^{\mathrm{d}}$ \\
\hline & $(\%)$ & $(\%)$ & $(\%)$ & $(\%)$ & $(\%)$ & $(\%)$ & $(\%)$ & $(\%)$ & $(\%)$ & $(\%)$ \\
\hline \multicolumn{11}{|c|}{ Average method ${ }^{a}$} \\
\hline Total & 78.7 & 56.5 & 30.6 & 68.8 & 86.7 & 77.9 & 7.7 & 25.0 & 95.3 & 83.6 \\
\hline \multicolumn{11}{|l|}{ Sex } \\
\hline Male & 72.2 & 66.7 & 45.5 & 64.2 & 81.1 & 75.0 & 14.3 & 50.0 & 95.2 & 76.9 \\
\hline Female & 83.3 & 37.5 & 14.6 & 71.3 & 89.7 & 79.6 & NC & NC & 95.3 & 87.2 \\
\hline \multicolumn{11}{|l|}{ School level } \\
\hline Primary & 67.8 & 53.6 & 40.5 & 62.7 & 74.0 & 71.4 & NC & NC & 100 & 75.0 \\
\hline Post Primary & 85.1 & 61.1 & 22.9 & 71.5 & 93.0 & 81.6 & 16.7 & 25.0 & 93.0 & 88.9 \\
\hline \multicolumn{11}{|c|}{ All days method ${ }^{b}$} \\
\hline Total & 90.2 & 60.9 & 16.5 & 66.5 & 94.0 & 90.2 & NC & NC & 93.4 & 98.6 \\
\hline \multicolumn{11}{|l|}{ Sex } \\
\hline Male & 88.7 & 66.7 & 22.7 & 58.5 & 90.6 & 92.9 & NC & NC & 92.9 & 100 \\
\hline Female & 91.3 & 50.0 & 9.8 & 71.5 & 95.9 & 89.8 & NC & NC & 95.8 & 97.9 \\
\hline \multicolumn{11}{|l|}{ School level } \\
\hline Primary & 93.1 & 61.5 & 21.6 & 60.8 & 90.0 & 96.4 & NC & $\mathrm{NC}$ & 100 & 100 \\
\hline Post Primary & 88.5 & 60.0 & 12.5 & 69.6 & 96.0 & 87.8 & NC & NC & 91.7 & 97.8 \\
\hline
\end{tabular}

NC not computable as no participants met the PAGL using all 7 days method

${ }^{a}$ Average method (AM): proportion achieving an average of 60 mins or more of MVPA across all valid days

${ }^{b}$ All days method (ADM): proportion achieving $\geq 60$ mins MVPA on (i) $\geq 5$ days (ii) 7 days

CPPV: positive predictive value

${ }^{\mathrm{d}} \mathrm{NPV}$ : negative predictive value

decline of PA during adolescence is a consistent finding in studies using self-report instruments [37] and has also been found using accelerometers [31].

Several limitations are present in this study. Firstly, there is no consensus on the most suitable accelerometer cut points to use for classifying MVPA in children or adolescents [41]. This study used Freedson cut points with moderate intensity $\geq 4 \mathrm{METs}$. However, correlations between self-report and accelerometer data are similar for MVPA derived from cut points and the CPM obtained from raw data (Table 3), and the correlation strength would be described in the same way. Secondly, lack of compliance with wearing the accelerometer meant relatively high numbers were excluded from the analysis $(56.1 \%$ compliance for $\geq 5$ days and $18.0 \%$ compliance for seven days). A small sample size within certain groups limited the ability to draw definitive conclusions (e.g. male and primary students $(n=28)$ when using the seven-day criterion). Nonetheless, the final sample size was similar to previous validation studies $[10,12,17]$. Third, the attainment of the PAGL was quite low across the study. This influenced the estimation of sensitivity and PPV.

\section{Conclusions}

Assessing non-compliance with PAGL is central to public health as it identifies the segment of the population that would benefit from increased PA. The PACE+ questionnaire was developed to identify youth not meeting PA recommendations. This study confirms the validity of the instrument for this purpose. Notably, validity is higher in females and older children. However, a series of different questionnaires for specific sex or age groups should be avoided, as the interpretation of youth population PA would be compromised. The ease of administration that this tool offers is vital for use at a population level [18]. The continued use of the questionnaire is recommended and will allow for comparability between studies, tracking of PA over time including trends in youth population prevalence. For more detailed information, it should be used alongside other measures that describe PA behaviour, e.g. measures for assessing specific types of physical activities.

\section{Abbreviations}

PA: Physical activity; PAGL: Physical activity guidelines; MVPA: Moderate to vigorous physical activity; ICC: Intraclass correlation coefficient; CPM: Counts 
per minute; AM: Average method; ADM: All days method; PPV: Positive predictive value; NPV: Negative predictive value.

\section{Competing interests}

The authors declare that they have no competing interests.

\section{Authors' contributions}

MHM was involved in study design, data collection, carried out statistical analysis and wrote the manuscript. DAR assisted with statistical methods and analysis, and reviewed the document. CBW assisted with the development of the concept and methodology, provided editing assistance for tables and content, and reviewed the manuscript. SB assisted with statistical methods, provided editing assistance for tables and content, and reviewed the manuscript. All authors read and approved the final manuscript.

\section{Acknowledgements}

This work was supported by the Irish Sports Council and part-funded by the School of Health and Human Performance, Dublin City University.

\section{Author details}

${ }^{1}$ School of Health and Human Performance, Dublin City University, Dublin 9, Ireland. ${ }^{2}$ School of Psychological Sciences and Health, University of Strathclyde, Glasgow, UK.

Received: 18 May 2015 Accepted: 13 October 2015

Published online: 23 October 2015

\section{References}

1. World Health Organization. Global recommendations on physical activity for health. Geneva, Switzerland: WHO; 2010.

2. Hallal PC, Andersen LB, Bull FC, Guthold R, Haskell W, Ekelund U. Global physical activity levels: Surveillance progress, pitfalls, and prospects. Lancet. 2012;380(9838):247-57.

3. Kohl HW III, Craig CL, Lambert EV, Inoue S, Alkandari JR, Leetongin G, et al. The pandemic of physical inactivity: Global action for public health. Lancet. 2012;380(9838):294-305.

4. Janz KF. Physical activity in epidemiology: Moving from questionnaire to objective measurement. Br J Sports Med. 2006;40:191-2.

5. Shephard RJ. Limits to the measurement of habitual physical activity by questionnaires. Br J Sports Med. 2003:37(3):197-206.

6. Milton K, Clemes S, Bull F. Can a single question provide an accurate measure of physical activity? Br J Sports Med. 2013:47(1):44-8.

7. Sarkin JA, Nichols JF, Sallis JF, Calfas KJ. Self-report measures and scoring protocols affect prevalence estimates of meeting physical activity guidelines. Med Sci Sports Exerc. 2000;32(1):149-56.

8. Warren JM, Ekelund U, Besson H, Mezzani A, Geladas N, Vanhees L. Assessment of physical activity - a review of methodologies with reference to epidemiological research: A report of the exercise physiology section of the European Association of Cardiovascular Prevention and Rehabilitation. Eur J Cardiovasc Prev Rehabil. 2010;17(2):127-39.

9. World Health Organization Europe. Report of the workshop on integration of data on physical activity patterns. Report No. 4. Zurich, Switzerland: WHO; 2009.

10. Ridgers ND, Timperio A, Crawford D, Salmon J. Validity of a brief self-report instrument for assessing compliance with physical activity guidelines amongst adolescents. J Sci Med Sport. 2012;15:136-41.

11. Biddle S, Sallis JF, Cavill NA. Young and active? Young people and health-enhancing physical activity: evidence and implications. London: Health Education Authority; 1998.

12. Prochaska JJ, Sallis JF, Long B. A physical activity screening measure for use with adolescents in primary care. Arch Pediatr Adolesc Med. 2001;155(5):554-9.

13. Fitzgerald L, Ozemek C, Jarrett H, Kaminsky LA. Accelerometer validation of questionnaires used in clinical settings to assess MVPA. Med Sci Sports Exerc. 2015:47(7):1538-42.

14. Garriguet D, Tremblay S, Colley RC. Comparison of physical activity adult questionnaire results with accelerometer data. Health Rep. 2015;26(7):11-7.

15. Vega-Lopez S, Chavez A, Farr KJ, Ainsworth BE. Validity and reliability of two brief physical activity questionnaires among Spanish-speaking individuals of Mexican descent. BMC Res Notes. 2014;7:29.
16. Troped PJ, Wiecha JL, Fragala MS, Matthews CE, Finkelstein DM, Kim J, et al. Reliability and validity of YRBS physical activity items among middle school students. Med Sci Sports Exerc. 2007;39(3):416-25.

17. Helmerhorst HJ, Brage S, Warren J, Besson H, Ekelund U. A systematic review of reliability and objective criterion-related validity of physical activity questionnaires. Int J Behav Nutr Phys Act. 2012(9).

18. Biddle SJ, Gorely T, Pearson N, Bull FC. An assessment of self-reported physical activity instruments in young people for population surveillance: Project ALPHA. Int J Behav Nutr Phys Act. 2011(8).

19. Currie C, Zanotti C, Morgan A, Currie D, de Looze M, Roberts C, et al. Social determinants of health and well-being among young people. Health Behaviour in School-aged Children (HBSC) study: International report from the 2009/2010 survey. Copenhagen: WHO Regional Office for Europe (Health Policy for Children and Adolescents, No. 6); 2012.

20. Guthold R, Cowan MJ, Autenrieth CS, Kann L, Riley LM. Physical activity and sedentary behavior among schoolchildren: A 34-country comparison. J Pediatr. 2010;157(1):43-9.

21. Peltzer K. Leisure time physical activity and sedentary behavior and substance use among in-school adolescents in eight African countries. Int J Behav Med. 2010;17(4):271-8.

22. World Health Organization. Global school-based student health survey (GSHS). http://who.int/chp/gshs/en/ Accessed 29 January 2015.

23. Woods CB, Tannehill D, Quinlan A, Moyna NM, Walsh J. The Children's Sport Participation and Physical Activity Study (CSPPA). Report No. 1. Dublin, Ireland: School of Health and Human Performance, Dublin City University and The Irish Sports Council; 2010.

24. Woods CB, Nelson NM, Foley E, O'Gorman D, Moyna NM. The Take PART study: Rationale and Methodology. J Phys Act Health. 2009;6(2):170-7.

25. Belton S, O'Brien W, Meegan S, Woods C, Issartel J. Youth-Physical Activity Towards Health: Evidence and background to the development of the Y-PATH physical activity intervention for adolescents. BMC Public Health. 2014;14:122

26. Rowe DA, Murtagh S. FifeActive - physical activity participation in Fife schoolchildren: Research report of current levels, modes, contexts, preferences and determinants. FifeActive: Glasgow; 2012.

27. Vuori M, Ojala K, Tynjala J, Villberg J, Valimaa R, Kannas L. The stability of physical activity survey items in the HBSC study. Liik Tiede. 2005;42(6):39-46.

28. Liu Y, Wang M, Tynjala J, LV Y, Villberg J, Zhang Z, et al. Test-retest reliability of selected items of Health Behaviour in School-aged Children (HBSC) survey questionnaire in Beijing, China. BMC Med Res Methodol. 2010;10:73.

29. Bobakova D, Hamrik Z, Badura P, Sigmundova D, Nalecz H, Kalman M. Test-retest reliability of selected physical activity and sedentary behaviour HBSC items in the Czech Republic, Slovakia and Poland. Int J Public Health. 2015;60(1):59-67.

30. Welk GJ. Principles of design and analyses for the calibration of accelerometry-based activity monitors. Med Sci Sports Exerc. 2005;37(11 Suppl):S501-11.

31. Trost SG, Pate RR, Sallis JF, Freedson PS, Taylor WC, Dowda M, et al. Age and gender differences in objectively measured physical activity in youth. Med Sci Sports Exerc. 2002;34(2):350-5.

32. Freedson P, Pober D, Janz KF. Calibration of accelerometer output for children. Med Sci Sports Exerc. 2005;37(11 Suppl):S523-30.

33. Trost SG, Loprinzi PD, Moore R, Pfeiffer KA. Comparison of accelerometer cut points for predicting activity intensity in youth. Med Sci Sports Exerc. 2011;43(7):1360-8.

34. Troiano RP, Berrigan D, Dodd KW, Masse LC, Tilert T, McDowell M. Physical activity in the United States measured by accelerometer. Med Sci Sports Exerc. 2008:40(1):181-8.

35. Cohen J. Statistical power analysis for the behavioral sciences. 2nd ed. Erlbaum Associates: Hillsdale, NJ; 1988.

36. Parikh R, Mathai A, Parikh S, Chandra Sekhar G, Thomas R. Understanding and using sensitivity, specificity and predictive values. Indian J Ophthalmol. 2008;56(1):45-50.

37. Dumith SC, Gigante DP, Domingues MR, Kohl HW III. Physical activity change during adolescence: A systematic review and a pooled analysis. Int J Epidemiol. 2011;40(3):685-98.

38. Chinapaw MJ, Mokkink LB, van Poppel MN, van Mechelen W, Terwee CB. Physical activity questionnaires for youth: A systematic review of measurement properties. Sports Med. 2010;40(7):539-63.

39. Loprinzi PD, Cardinal BJ. Measuring children's physical activity and sedentary behaviors. J Exer Sci Fit. 2011;9(1):15-23. 
40. Adamo KB, Prince SA, Tricco AC, Connor-Gorber S, Tremblay M. A comparison of indirect versus direct measures for assessing physical activity in the pediatric population: A systematic review. Int J Pediatr Obes. 2009;4(1):2-27.

41. Kim Y, Beets MW, Welk GJ. Everything you wanted to know about selecting the "right" Actigraph accelerometer cut-points for youth, but...: A systematic review. J Sci Med Sport. 2012;15(4):311-21.

Submit your next manuscript to BioMed Central and take full advantage of:

- Convenient online submission

- Thorough peer review

- No space constraints or color figure charges

- Immediate publication on acceptance

- Inclusion in PubMed, CAS, Scopus and Google Scholar

- Research which is freely available for redistribution 